\title{
High-resolution computed tomography with three-dimensional reconstruction for assessment of chronic pulmonary thromboembolic disease
}

Thoralf M. Sundt, MD, ${ }^{\mathrm{a}}$ and Eric E. Williamson, $\mathrm{MD}^{\mathrm{b}}$

This 60-year-old man developed progressive dyspnea on exertion and was found to have pulmonary hypertension on echocardiography (estimated right ventricular pressure 91 $\mathrm{mm} \mathrm{Hg}$ ). Pulmonary thromboembolic disease was diagnosed by computed tomography (CT) as shown in Figure 1. Hematologic evaluation revealed essential thrombocytopenia and $J A K 2 \mathrm{~V} 617 \mathrm{~F}$ mutation positivity. The patient was referred for pulmonary thromboendarterectomy, which he underwent successfully (Figure 2). Preoperative pulmonary arterial pressures with the patient under general anesthesia were 63 $\mathrm{mm} \mathrm{Hg}$ systolic and $23 \mathrm{~mm} \mathrm{Hg}$ diastolic, mean $37 \mathrm{~mm} \mathrm{Hg}$, with a cardiac output of $5.8 \mathrm{~L} / \mathrm{min}$. Postoperative pulmonary arterial pressures were $42 \mathrm{~mm}$ systolic and $16 \mathrm{~mm} \mathrm{Hg}$ diastolic, mean $26 \mathrm{~mm} \mathrm{Hg}$, at a cardiac output of $6.1 \mathrm{~L} / \mathrm{min}$.

With advances in high-resolution CT scanning, we have migrated away from pulmonary arteriography in the preoperative evaluation of patients with chronic pulmonary thromboembolic disease. High-resolution CT also provides a simple means of evaluating the operative result before discharge from the hospital (Figure 3). Scans are performed with electrocardiographic gating with a dual-source 128-row scanner (Siemens AG Healthcare Sector, Erlangen,

From the Division of Cardiovascular Surgery ${ }^{\mathrm{a}}$ and the Department of Radiology, ${ }^{\mathrm{b}}$ Mayo Clinic, Rochester, Minn.

Disclosures: Authors have nothing to disclose with regard to commercial support.

Received for publication Jan 20, 2011; accepted for publication Feb 9, 2011; available ahead of print March 23, 2011.

Address for reprints: Thoralf M. Sundt, MD, Mayo Clinic, 200 First St SW, Rochester, MN 55905 (E-mail: sundt.thoralf@mayo.edu).

J Thorac Cardiovasc Surg 2011;141:1539-40

$0022-5223 / \$ 36.00$

Copyright (C) 2011 by The American Association for Thoracic Surgery

doi:10.1016/j.jtcvs.2011.02.003

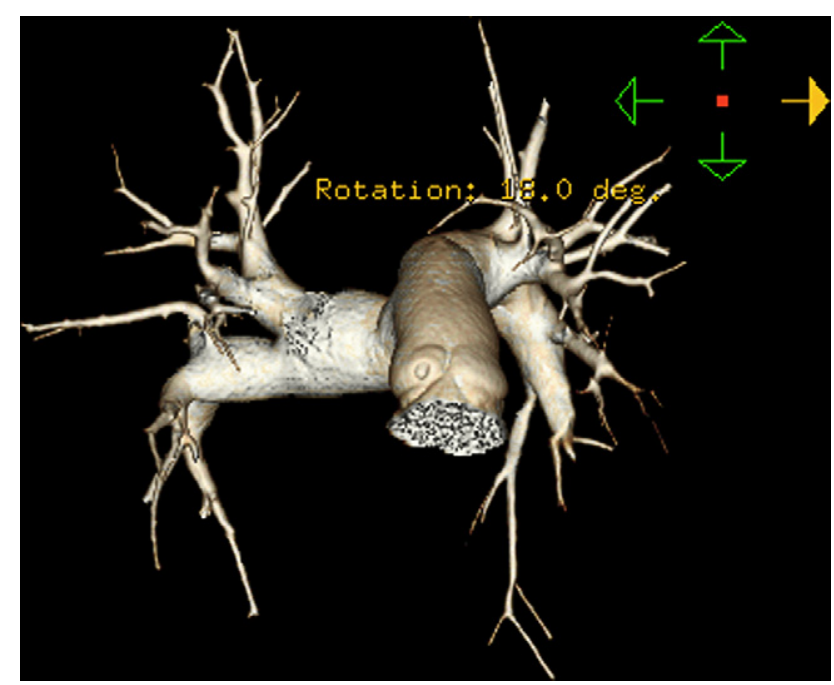

FIGURE 1. Preoperative volume-rendered 3-dimensional computed tomographic image demonstrating proximal disease bilaterally.

Germany). A biphasic injection protocol is used, including $80 \mathrm{~mL}$ of iodinated contrast medium followed by $80 \mathrm{~mL}$ of a 50:50 mix of contrast medium and saline solution at an injection rate of $5 \mathrm{~mL} / \mathrm{s}$. The $\mathrm{CT}$ acquisition is triggered by bolus tracking with a region of interest in the main pulmonary artery, and images are acquired from the top of the lungs through the lung bases. Thin-section reconstructions are performed $(1.5 \mathrm{~mm}$ thick at $1-\mathrm{mm}$ increments) and used to produce the volume-rendered 3-dimensional images. Additional axial and short-axis multiphase images are reconstructed ( $6 \mathrm{~mm}$ thick at $3-\mathrm{mm}$ increments) and used for the measurement of right ventricular volumes and function.
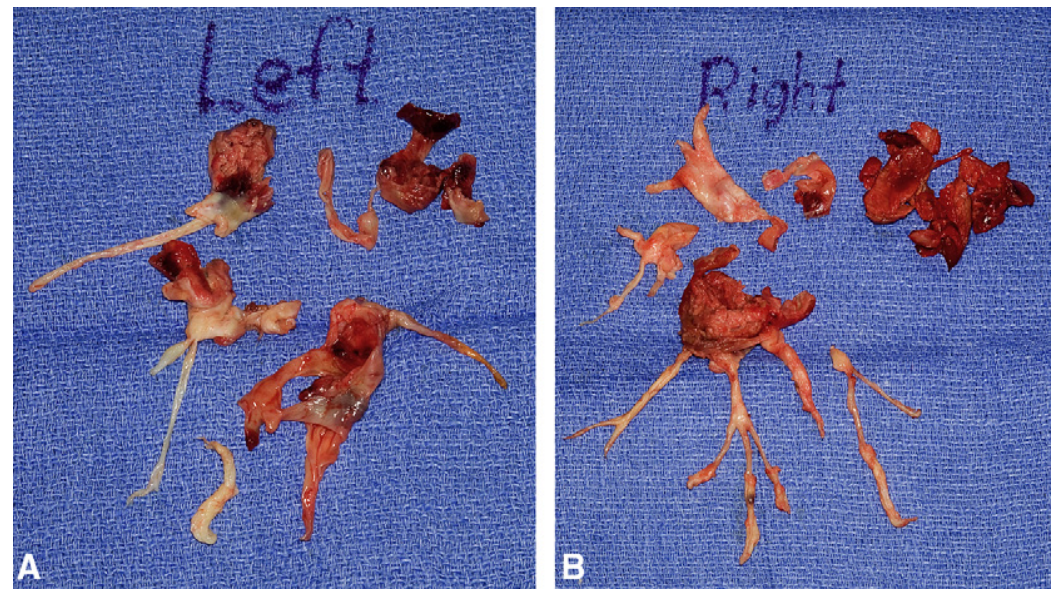

FIGURE 2. Intraoperative specimens from left (A) and right (B) pulmonary arteries. 


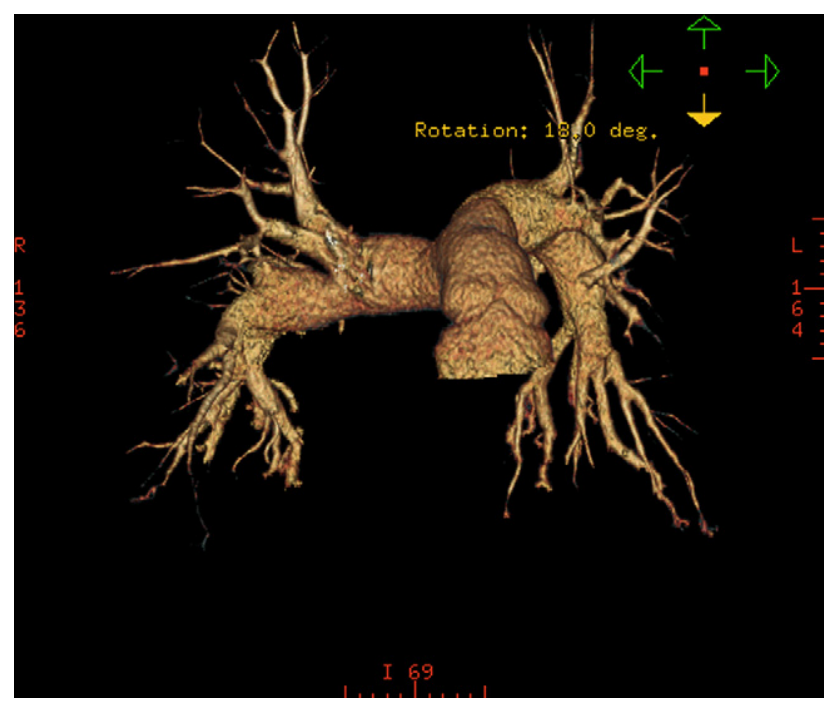

FIGURE 3. Postoperative result, as demonstrated by volume-rendered 3-dimensional computed tomographic image. 